科 学 通 报

\title{
香港贝澳湾全新世海滩岩的发现及意义*
}

\author{
王 为 \\ （香港大学地理地质系）
}

\section{关镜调 海滩岩、沙塨、海平面}

\section{1 海滩岩的位置、高程与年代}

贝澳湾是香港地区大嫁舟(大屿山)南岸向西南开口的小海湾(图 1(a)), 宽约 $1 \mathrm{~km}$, 湾内 现代沙堤堤顶高 $4.5 \mathrm{~m}^{1)}$. 堤后渴湖大部分已干涸, 现代沙堤之后约 $120 \mathrm{~m}$ 有一条平行的古沙 堤, 高程为 7-6m. 贝澳海滩岩埋藏于古沙堤东端及干潟湖之下(图 $1(\mathrm{~b})$ ), 厚 $70-80 \mathrm{~cm}$. 其 中至少可分上、中、下三层,各层具斜层理或交错层理,主要成分为石英砂、砾及贝壳碎屑, 层间 为松散或半胶结的石英砂及贝屑. 由上至下各层贝壳的 $\mathrm{C}^{14}$ 年代分别 为 $1700 \pm 80 \mathrm{aB} . \mathrm{P}$., $2380 \pm 90$ aB.P., $2820 \pm 95 \mathrm{aB}$. P. 海滩岩之上约 $10 \mathrm{~cm}$ 厚的贝壳层为 $1630 \pm 65 \mathrm{aB}$. P.(图 2).

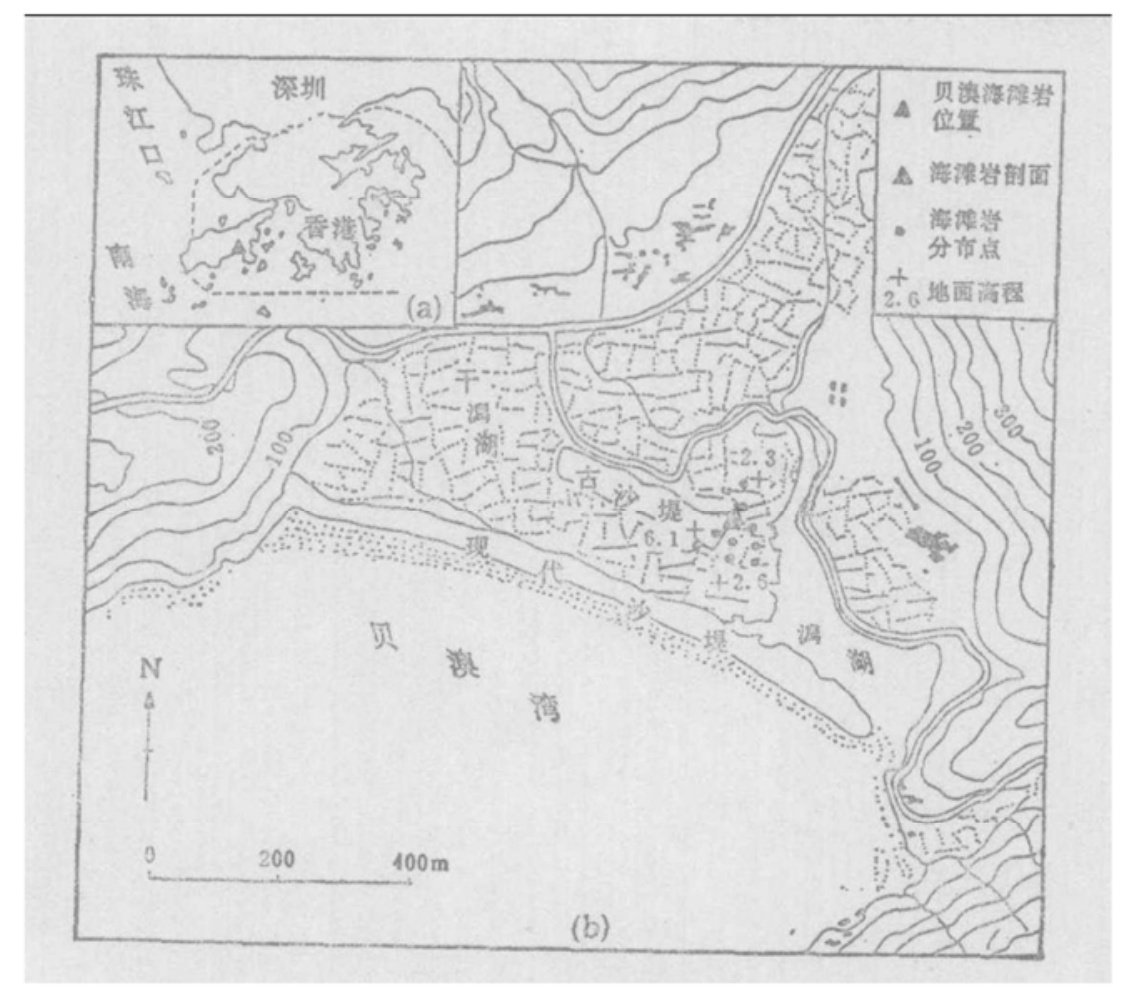

图 1 贝溜湾海滩岩位置图

1992-06-15 收稿, 1992-10-07 收修改稆.

* 国家自然科学基金资助项目.

1) 本文所用高程基准面是香港政府土地测胆基准面, 高于香港海图北准面 $0.146 \mathrm{~m}$. 


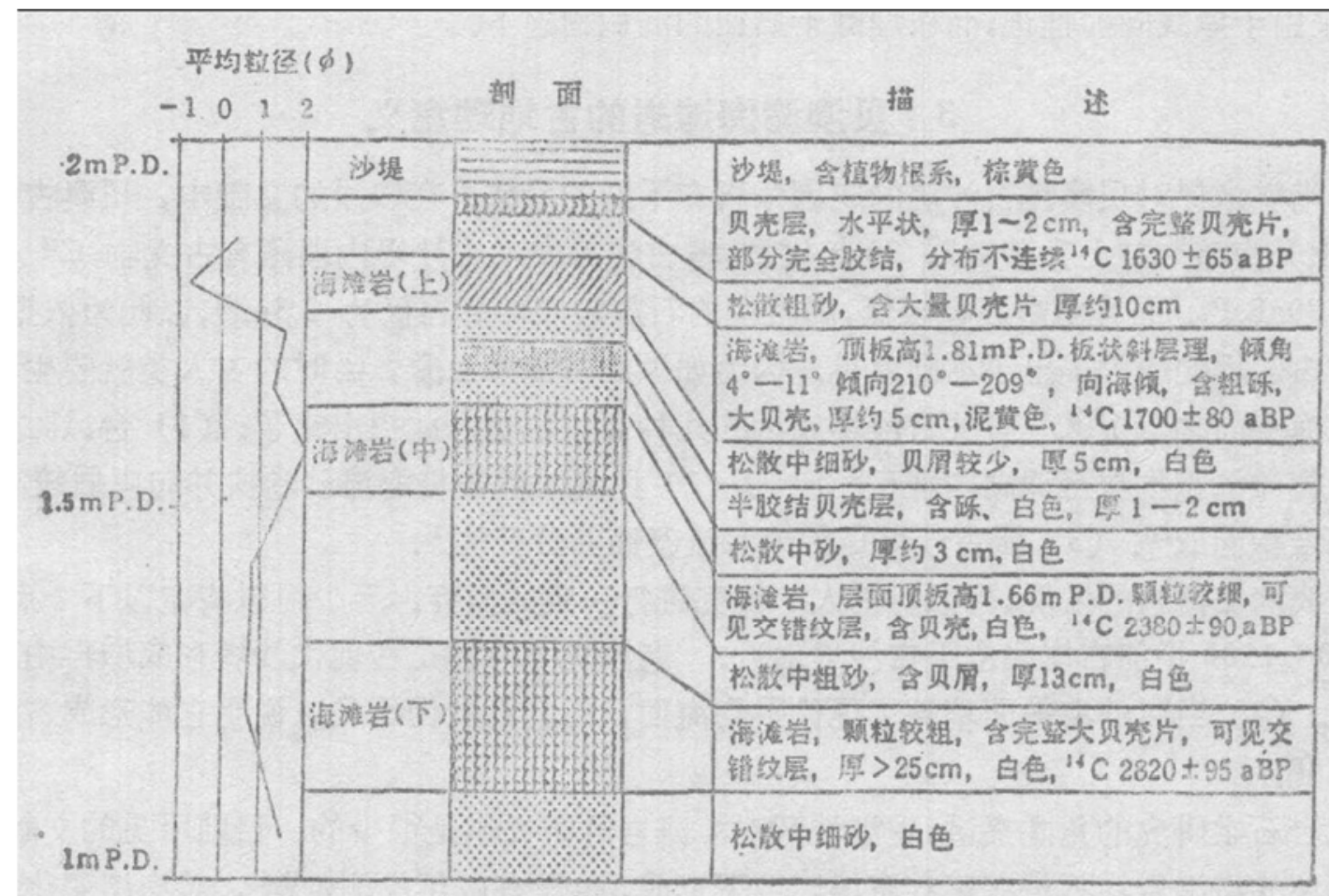

图 2 海滩岩剖面描述

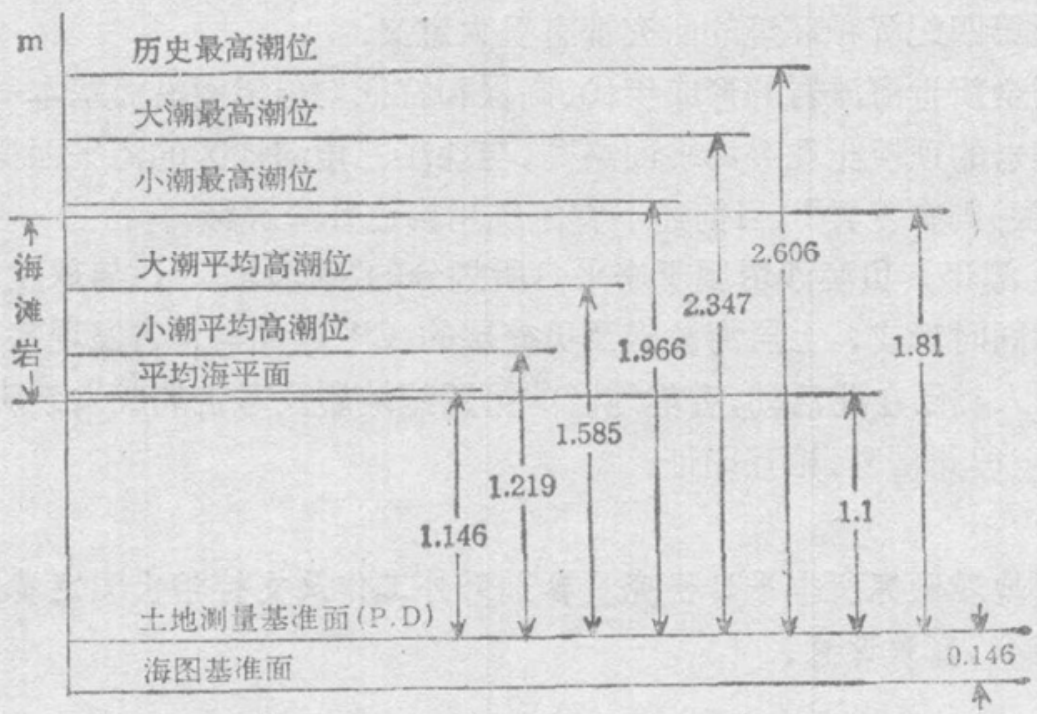

图 3 海滩岩高变与高潮潮位的关系

对上、中两层海滩岩顶板进行水准测量,其高程分别为 1.82 和 $1.66 \mathrm{~m}$,下层底板高程约 1.1 $\mathrm{m}$, 比现代平均海面 $1.146 \mathrm{~m}$ 稍高, 而上层顶板高程仍在最高潮位之下(图 3).

\section{2 海滩岩胶结物及所反映的形成环境}

在偏光镜下,海滩岩胶结物可分为两个时期,第一期胶结物为环绕颗粒的柱状方解石, 形 成于成淡混合之潜水带的海滩环境, 第二期胶结过程中第一期胶结物已被溶蚀成孔洞, 而颗粒 间空隙被粒状方解石充填, 这是一种埋藏环境下的胶结特征, 说明海滩岩先在海滩环境下胶 
结,后来由于岸线向前推进,而被埋藏于后期的沉积物之下.

\section{3 贝澳湾海滩岩的古地理意义}

香港学术界对贝澳湾古沙堤的成因一直有不同的看法. 在较早的文献中, 贝澳古沙堤被 称为“上升海滩”或“上开砂㗪”, 80 年代后,考古学界发现古沙堤内埋藏有古文物 $\mathrm{C}^{14}$ 测年为 $1610 \pm 70 \mathrm{aB}$. P., 而且出露高程较低, 同时代的石灰蜜底部高程仅为 $2.3 \mathrm{~m}^{\text {以 }}$, 以此为依据, 有些 学者对古沙堤的成因提出了不同意见. 因为如果是古海滩上升, 当时的古人类就要生活在潮 间带或海平面之下了 ${ }^{[2]}$. 有关古沙堤成因的几种新假说也因此提出来了:（1）台风时强风扎 河口及海滩沉积物吹至潟湖内堆积而成 ${ }^{[3]}$. (2) 风暴时巨浪将海滩砂卷挟并向岸后较高较 远 地抛掷堆积而成 ${ }^{[4]}$. (3) 新古沙堤是因为河流侵蚀而分开的 ${ }^{[3]}$.

贝澳湾海滩岩的发现,可以对前人的研究进行一定的扬弃. 至少可以肯定以下 2 点:（1) 在 2800-1500 年前古岸线位于古沙堤附近. 老沙堤不可能是在现代沙堤形成后再由风或巨 浪形成.（2）当时的海平面稍高于现代平均海面, 但其高度仍不足以说明它能形成古沙堤现 在的高度。

就岩石学研究的角度来讲, 香港地区对海滩岩的研究还是很少的. 目前所见的文献中, 过 去所发现的海滩岩均不是在正常海滩环境下形成, 也没有做年代测定 ${ }^{[5,6]}$, 对海岸变化研究没 有很大意义. 贝澳湾海滩岩的发现及研究不仅对贝澳海滩岩及沙堤本身, 同时对香港地区各 处的古沙堤成因及第四纪沉积环境的研究都有重大意义.

（1）香港地区全新世海滩岩的形成年代、高程和特征均与华南沿海基本一致以.

（2）贝澳海滩岩的顶板比现今海平面略高, 与珠江三角洲地区的海平面变化基本一致,伯 某些时段(例如中层) 则有差异 ${ }^{[01}$,目前还不宜笼统用构造升降解释,有待进一步工作.

（3）根据 $\mathrm{C}^{14}$ 测作, 贝澳沙堤属于李平日所划分的“新沙堤”[1]，与珠江口的横琴、淇澳 及中山的沙堤基本同时形成, 上层海滩岩及贝壳层的 $\mathrm{C}^{14}$ 年代与考古发现基本一致. 即距今 约 1700-1500a., 人毴已在此活动,香港地区的第四纪地质及考古的成果表明, 它们同属珠江 口范畴,许多问题应彼此借鉴,相互印证.

致谢广州地理研究所本平日研究员参加野外工作及支持年代测定费用; 讪炎基高级 工程师测定 $\mathrm{C}^{14}$ 年代, 谨致谢意.

\section{参考文献}

[1] Meachan, W., Pui, O., Jour. Hong Kong Archaeological Society, 1984-1985, XI: 113-118.

[2] Liu, K. U., Gammon, J. R. A., in Geology of Surticial Deposits in Hong Kong (eds. Yim, W. W. S. es al.), Geol. Soc. Hong Kong Bull., 1984.

[3] Meachan, W., Yim, W. W. S., Jour. Hong Kong Archacological Society, 1982-1983, VX: $70-71$.

[4] 露健堆,热带海洋, 1987,6(1): 19-27.

[5] Tschang, H. L., Chong Chi Journal, 1962, (1): 117-122.

[6] Strange, P. T., Geological Society of Hong Kong, 1986, 4(2): 13-16.

[ 7] 李平日,海洋地质与第四纪地质, $1988,8(4): 21-29$.

[8] 本平日等,珠江三角洲一万年来环境演变,海洋出版社,北京, 1991,59-66.

[9] 本平日,科学通报, $1989,34(12): 928-931$. 